\title{
Will the Steam Coal Price Rebound under the New Economy Normalcy in China?
}

\author{
Xiaopeng Guo ${ }^{1, *}$, Yanan Wei ${ }^{1,2}$ and Jiahai Yuan ${ }^{1}$ \\ 1 School of Economics and Management, North China Electric Power University, No. 2 Beinong Road, \\ Changping District, Beijing 102206, China; 142206059@ncepu.edu.cn (Y.W.); yuanjiahai@ncepu.edu.cn (J.Y.) \\ 2 Yunnan Electric Power Science Research Institute, No. 105, Yunda Western Road, Kunming 650217, China \\ * Correspondence: g_2010_xp@ncepu.edu.cn; Tel.: +86-135-2032-8997
}

Academic Editor: Francisco Martínez-Álvarez

Received: 7 June 2016; Accepted: 5 September 2016; Published: 15 September 2016

\begin{abstract}
The steam coal price in China has been continuously decreasing since the second half of 2012. Constant low price of coal will accelerate the development of thermal power, cause more serious air pollution problems, and bring adverse influence to China's energy reformation in the future. Therefore, analyzing the factors underlying the phenomenon of the decreasing steam coal price is significant. In this study, we first qualitatively analyze five main factors, namely, economy, supply, demand, substitutes, and port stocks. On the basis of the relationships among these five factors, we obtain the causality diagram and the system flow diagram of coal price for further quantitative research. Then, we conduct an empirical analysis using the system dynamics (SD) method and determine the simulated price from 2012 to 2017. Finally, we discuss the running results and come to the conclusion that the steam coal price will continue to decrease under the combined actions of the five main factors and it will not rebound in the near future.
\end{abstract}

Keywords: steam coal price; factor analysis; system dynamics (SD) method; supply-demand

\section{Introduction}

The acceleration of industrialization and urbanization of China has resulted in increasingly evident air pollution problems, particularly in Beijing, Tianjin, and Hebei Provinces. Atmospheric pollutants, such as PM 10 and PM 2.5, have seriously affected the urban environment and quality of life of local residents. Thus, controlling air pollution is imperative.

Electricity and coal are important in China's energy industry. Coal is the main energy source in China and accounted for $66 \%$ of total energy consumption in 2014 [1]. Moreover, $70 \%$ of coal is used for power generation in recent years. Dust, $\mathrm{SO}_{2}$, and $\mathrm{NO}_{x}$ emissions caused by steam coal combustion accounted for $23.27 \%, 44.88 \%$ and $64.40 \%$ of the total national emissions in 2012 , respectively, and $\mathrm{CO}_{2}$ emission accounted for $43.77 \%$ [2]. Consequently, atmospheric pollution, and energy conservation problems caused by combustion of steam coal are the key to air pollution control and energy conservation work in China.

At present, China's economy has entered a new normalcy and the times of relying on high investment, high pollution, and high return have gone [3]. The new economy normalcy in China is an impetus that turns quantity expansion into quality promotion, turns production factors into technological innovation, and turns the purely high-speed rate into the high/middle-speed rate. All these changes are associated with energy consumption. In this case, energy demand intensity decreases, coal demand growth slackens, overcapacity becomes serious, and development mode relies on expansion stopping.

Based on the subsistent atmospheric pollution problems and the structural adjustments of the economy in China, mining technology, price trends, demand patterns, and total consumption of coal 
have all been affected. The steam coal price in China continued to decrease dramatically since the second half of 2012. The price spread of key contract coal and market coal is narrowing, even to the point that the key contract coal price is higher than market coal price. The government officially canceled the dual pricing system of coal in January 2013 as a reaction to this unprecedented relationship of the supply and demand of steam coal. Therefore, coal and power generation enterprises have linked up autonomously to negotiate prices. In this way, the market plays an important part in the resource allocation of steam coal.

In the second half of 2012, the steam coal price of $5500 \mathrm{kcal}$ in Bohai Rim decreased from 774 yuan/ton (May) to 635 yuan/ton (December), and the decrease amplitude reached 18\%. Then, the steam coal price continued to decrease. Although virtual heights occurred at the end of 2013 and 2014, the steam coal price kept decreasing in the next year. At present, we cannot see signs of a price rebound in China according to existing price data until May 2016 [4]. The golden decade (2002-2011) of the coal industry in China has been completely broken by the long-lasting plummet of steam coal prices. In this case, the profits of many coal enterprises and the costs of coal-fired power were significantly reduced and several thermal power plants experienced a turn from loss to profit. Figure 1 shows the monthly price data of steam coal in Bohai Rim from January 2012 to March 2016.

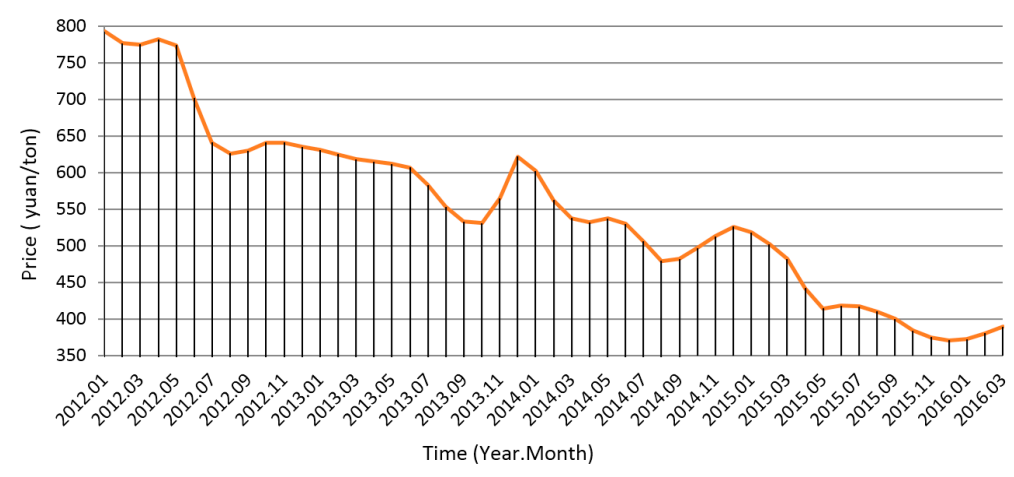

Figure 1. Monthly price of steam coal in Bohai Rim.

By using the system dynamics (SD) method, this study examines the reasons for the long-lasting plummet of the steam coal price since 2012, and on this basis, forecasts the steam coal price trend in the near future. Section 2 qualitatively analyzes five factors of steam coal prices, namely, economy, demand, supply, substitutes, and inventory in ports. Section 3 proposes the SD model for steam coal price. Section 4 conducts an empirical analysis (including steam coal price prediction) based on related data from 2012 to 2017. Section 5 discusses the innovation points of our research, analyzes the downward trend of the steam coal price, and points out the practical application values of this paper. Section 6 concludes the paper and offers directions for future research.

The supply-demand and price problems of Chinese steam coal are more important under the background of the new normalcy of economy and air pollution prevention and control work. Compared with small cycle fluctuations in the period of the golden decade of the coal industry, this long-lasting plummet of steam coal price is obviously different. Thus, investigating the influencing factors behind this phenomenon is worthwhile and significant. This study has a promoting effect on convergence and coordination among production, transportation, and use of steam coal. It is conductive for coal enterprises to control capacity reasonably, conductive for electric power enterprises to adjust demand effectively, and conductive to promote the optimal allocation of domestic market resources of steam coal.

In recent years, some academics have conducted research on energy price volatility. Hasan et al. [5] used Generalized AutoRegressive Conditional Heteroskedasticity (GARCH) models to estimate and compare the asymmetry and persistence of volatility of crude oil, natural gas, and coal. Wang and $\mathrm{Wu}[6]$ forecasted energy market volatility by using multivariate and univariate 
GARCH-class models. Goor and Scholtens [7] applied GARCH models in the UK gas market. Kanamura [8] proposed a new volatility model model for energy prices using the supply-demand relationship. Zhang and $\mathrm{Mu}$ [9] built an econometric model to analyze the factors of Chinese port steam coal price. Wang et al. [10] used price discovery theory and time series analysis methods to examine the Chinese coal market. Zhang and Luo [11] and Zhou and Luo [12] investigated the interrelationship between international and Chinese energy price volatilities by using vector autoregression (VAR) models. He and Li [13], Weng [14] and Joëts and Mignon [15] tested the long-term related relationships of major energy prices through cointegration tests. García-Martos et al. [16] built a multivariate model for fossil fuel prices, $\mathrm{CO}_{2}$ prices, and electricity prices and compared its results with those of the univariate model. Zaklan et al. [17] conducted a comprehensive multivariate cointegration analysis of export, transport, and import prices.

Moreover, several scholars have analyzed the energy policy aimed at the Chinese coal market and air pollution problems. Wang et al. [18] pointed out that future energy policy should be transformed from "energy saving amount" into "total amount control". Ouyang and Lin $[19,20]$ discussed the renewable energy subsidies and fossil fuel subsidies in China. In addition, scholars are devoted to studying the relationship of energy demand and price. Yuan et al. [21] analyzed the relationships between Chinese energy consumption and energy price using econometric methods. Lee and Chong [22] used causal relationships to determine the effects of energy sources and prices on carbon emissions. Zhao et al. [23] investigated the long-term stable cointegration relationships between energy consumption and several relevant factors.

SD method is mostly used in chemistry, physics, and ecology, and some scholars also utilize this model in the field of energy. $\mathrm{Xu}$ and Li [24] developed a system dynamics with fuzzy multiple objective programming (SD-FMOP) model to examine the complex interactions in the coal industry system of China. Yu and Wei [25] proposed a hybrid model based on genetic algorithm and SD for coal production-environmental pollution load in China. Sverdrup et al. [26] built a copper SD model and analyzed world supply and turnover of copper. Ansari and Seifi [27] used the SD method to analyze steel demand, production, and energy consumption in an integrated framework. Chi et al. [28] investigated the indigenous natural gas industry in the UK by using the SD approach. Špicar [29] used the SD method in capacity planning, which involves the relationship between supply, demand, and price.

We observe that many scholars choose methods of statistics and econometrics to assess energy price volatility. However, this study mainly examines changes in the steam coal price, which is different from conventional volatilities in the energy market. To the best of our knowledge, several SD models have emerged in the field of energy research, but few scholars have directly used the SD method to examine the factors of steam coal price.

\section{Factor Analysis}

\subsection{Gross Domestic Product Growth Slowed Down}

In recent years, China's economic growth has slowed down. The year-on-year growth rate of gross domestic product (GDP) in 2012 was $7.7 \%$, which was initially less than $8 \%$ since this century. This decline marked the entry of the economy of China into a new normalcy. As the economy slowed down, many industries, such as coal, electricity, and steel, were affected. Consequently, this situation resulted in the decline of coal demand directly or indirectly.

The total generating capacity of 2012 was 4986.5 billion $\mathrm{kWh}$, increasing by $5.41 \%$ year-on-year, and the growth rate obviously decreased when compared with the $9.95 \%$ of the previous year. In this case, thermal power was seriously affected. Thermal power generating capacity in 2012 was 3926 billion $\mathrm{kWh}$, only increasing by $0.65 \%$, and the growth rate significantly decreased. Installed capacity was 820 million $\mathrm{kW}$, increasing by $6.68 \%$, but the growth speed decreased. Newly installed capacity was 52.36 million $\mathrm{kW}$, decreasing by $16.1 \%$ year-on-year. Power investment 
was 100.2 billion yuan, decreasing by $11.55 \%$ year-on-year. Annual utilization hours of the large capacity generating set was reduced by $323 \mathrm{~h}$ [30]. Thus, the economic downturn reduced the demand for thermal power from 2012 and affected the demand and price of steam coal. In addition, under the influence of new economy normalcy, the phenomenon of scant demand of coking coal also occurred in the iron and steel industry, which indirectly affected the steam coal price.

\subsection{Coal Overcapacity}

Since this century, China's coal industry has significantly developed with capacity expansion and production increase. Figure 2 shows the raw coal production and productivity growth rate from 2002 to 2015.

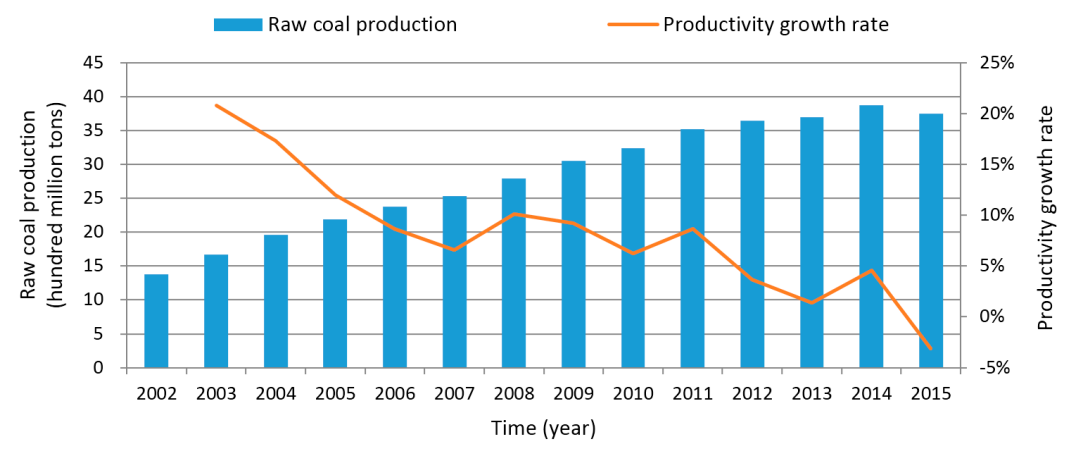

Figure 2. Historical data of raw coal production and productivity growth rate.

We can see that China's raw coal production continues to increase from 1.38 billion tons (2002) to 3.52 billion tons (2011) during the golden decade, with the productivity growth rate always being more than $6 \%$. However, in 2012, the growth rate suddenly decreased to $3.69 \%$. Production restriction occurred in large-scale coal mines, whereas several small mines were forced to shut down. The situation of the coal industry's overcapacity was particularly prominent. In the next three years, raw coal production reached 3.7, 3.87, and 3.75 billion tons, respectively, with the growth rate always being less than $5 \%$ and initially being negative in 2015 . Based on the overheated investment of coal in past 10 years, coal production since 2012 remained high despite the low growth rate. Excessive supply would result in the decline of the steam coal price.

\subsection{Weak Demand for Thermal Power}

In recent years, with the rapid development of new energy power, the proportion of thermal power capacity installed has been crowded out to a certain extent. Table 1 shows the installed capacity and its year-on-year growth rate of different power generation modes [30], including thermal, hydro, nuclear, wind, and solar, from 2011 to 2014 . We can see that although thermal power installed capacity occupied the leading edge, its year-on-year growth rate was always lower than other power generation modes, especially new energy power.

Table 1. Different installed capacity and its year-on-year growth rate.

\begin{tabular}{ccccccccc}
\hline Index & Power & $\mathbf{2 0 1 1}$ & $\mathbf{2 0 1 2}$ & $\begin{array}{c}\text { Year-on-Year } \\
\text { Growth }\end{array}$ & $\mathbf{2 0 1 3}$ & $\begin{array}{c}\text { Year-on-Year } \\
\text { Growth }\end{array}$ & $\mathbf{2 0 1 4}$ & $\begin{array}{c}\text { Year-on-Year } \\
\text { Growth }\end{array}$ \\
\hline Installed & thermal & 768 & 820 & $6.8 \%$ & 870 & $6.1 \%$ & 924 & $6.2 \%$ \\
capacity & hydro & 233 & 249 & $6.9 \%$ & 280 & $12.4 \%$ & 305 & $8.9 \%$ \\
(GW) & wind & 46 & 13 & $0.0 \%$ & 15 & $15.4 \%$ & 20 & $33.3 \%$ \\
& solar & 2 & 3 & $32.6 \%$ & 77 & $26.2 \%$ & 97 & $26.0 \%$ \\
\hline
\end{tabular}


In addition, the policy of energy-saving and emission-reduction also had an influence on thermal power industry. During the "12th Five-Year Plan" (2011-2015), the targets for thermal power industry are to decrease steam coal consumption by $8 \%$, sulfur dioxide emissions by $16 \%$, and nitrogen oxide emissions by $29 \%$ and to eliminate small thermal power units of 20 million $\mathrm{kW}$. The policy contributed to the efficient development of the power industry. However, at the same time, coal demand reduced, which resulted in the decline of coal price.

\subsection{Effect of Substitutes}

The import tariff rate of steam coal in China decreased from $6 \%$ to $3 \%$ on 1 April 2005, to $1 \%$ on 1 November 2006, and $0 \%$ on 1 June 2007. With the import tariffs being phased out year-by-year and the lower fares of international shipping, the price of imported coal gradually decreased and the quantity gradually increased. In 2009, China became a net importer of coal for the first time. Figure 3 shows the imported coal quantity and the growth rate from 2008 to 2015 [31].

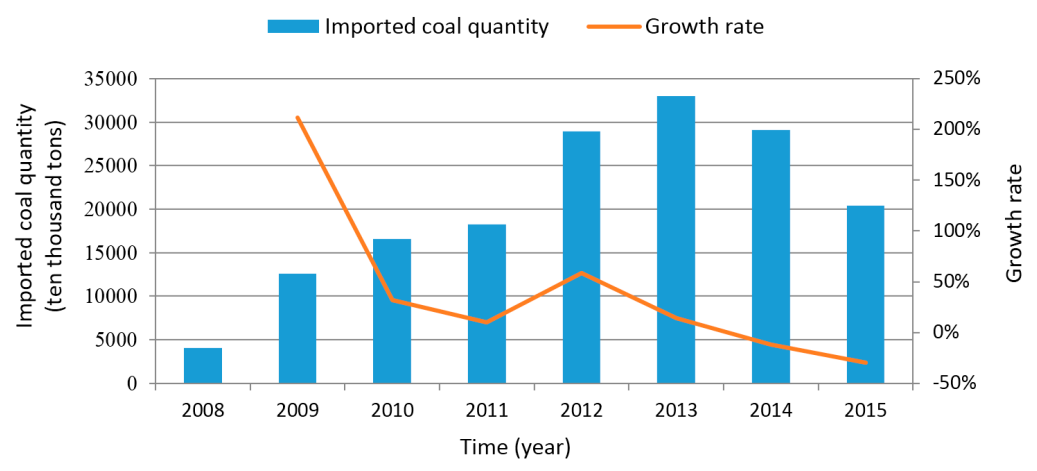

Figure 3. Historical data of imported coal quantity and the growth rate.

From Figure 3, we can see that the quantity of imported coal reached 289 million tons in 2012 , increasing by $58.6 \%$ year-on-year. The quantity in 2013 continued increasing to 330 million tons. Substantial increase of imported coal accounted for the market share of domestic coal; thus, the steam coal price in China was affected. However, domestic coal price has decreased sharply since 2012. In this case, the zero tariff policy on imported coal has been cancelled since 15 October 2014, which inhibited the market of imported coal to a certain extent, just as the quantity decreased year by year in 2014 and 2015.

In addition, with the promotion of energy conservation and emission reduction, oil and natural gas have been the new direction of energy development in China and will affect the demand and price of steam coal [10]. Besides, the volatility of international oil prices usually has an effect on international and domestic coal prices, and coal prices will follow the tendency of oil price volatility in the near future [11].

\subsection{High Stocks of Port Coal}

The imbalance between steam coal supply and demand is usually characterized by stocks, including coal enterprise and power plant inventories, and port stocks, which account for the greatest proportion. As the "wind vane" of China's steam coal price, the Qinhuangdao port coal stocks exhibited an upsurge at the beginning of the plummet of steam coal prices. The coal stocks in Qinhuangdao soared from 5.6 million tons to 9.08 million tons during the months of May and June in 2012, and the growth amplitude reached $62 \%$. The high port stock shows a backlog of steam coal because of the imbalance between supply and demand. Port stock is negatively related to steam coal price; the higher the inventory is, the lower the price will be. 


\section{Model Description}

\subsection{System Dynamics Methodology}

SD is an integrated methodology covering systems theory, management science, and simulation technology. It is mainly used to assess feedback mechanisms in a system using qualitative and quantitative analyses. This method can be used in many fields, such as nature, society, and the economy.

Our SD model for steam coal price is divided into two parts: qualitative analysis and quantitative analysis. The causality diagram is mainly used for the qualitative analysis and the system flow diagram is used to realize the quantitative analysis. The causality diagram achieves a qualitative analysis of complex correlations and influences within various factors of the steam coal price system by drawing system factors and the positive or negative causal chains connecting factors. The system flow diagram builds up the quantitative analysis model to simulate and analyze the system's behavior by drawing the visual state variable, the rate variable, and the auxiliary variable, and setting function relationships and initial values among variables through the Vensim software (Vensim PLE for Windows Version 6.2 $(\times 32)$, Ventana Systems, Inc., Cambridge, MA, USA).

Compared with other classical econometric approaches, SD is mainly used to research the feedback mechanisms within a system. The long-lasting plummet of steam coal prices is determined by multiple factors, and the interactions among these factors are dynamic and complex. There are complicated feedback mechanisms within the steam coal price system, so it is difficult to find a linear or nonlinear relationship between coal price and other factors by using econometric methods. Moreover, SD method has an advantage in solving dynamic problems because it can better describe the change characteristics of system factors at different time points. So this study uses SD to analyze the main factors causing the long-lasting plummet of the steam coal price since the second half of 2012, simulating the price from 2012 to 2017.

\subsection{Causality Diagram}

The five main factors of coal price interact with each other. For instance, a causal relationship exists between economic downturn and insufficient demand. Substitutes will affect the demand for domestic coal. Overcapacity in the coal industry is not only related to excessive investment but also to weak demand. The market price is codetermined by supply and demand, and the co-actions of oversupply and scant demand directly cause high port stocks, thereby foreboding the decline in coal price. Through the causality diagram, we can clearly see the casual relationship of various factors, as shown in Figure 4. (Note: approximately $70 \%$ of coal is used for power generation, and steam coal price is generally considered coal price in the market; thus, we use "coal price" to represent "steam coal price" in the model.)

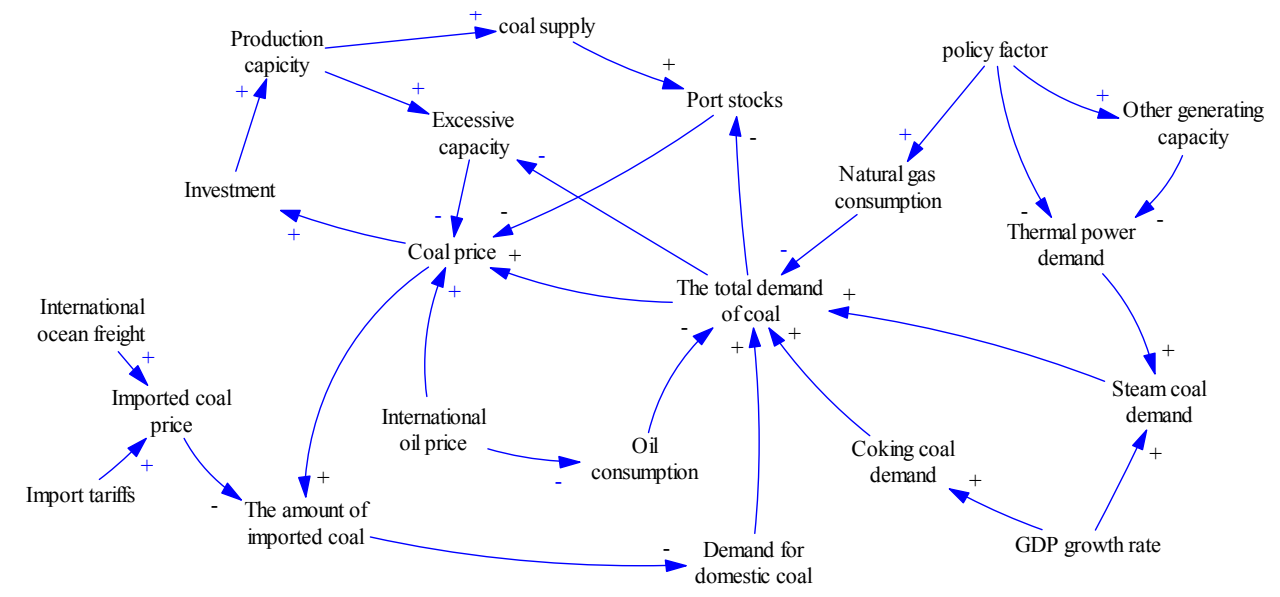

Figure 4. Causality diagram of coal price. 
In the causal relationship diagram, " + " means accelerating function and " - " means suppressive function between two factors according to the direction of the arrow. We can draw the following points from the causal relationship diagram of coal price: (1) during the golden decade of coal, production capacity continued to increase as investment increased for the coal industry. This growth consequently resulted in excessive capacity and lower prices. Furthermore, reduction of coal demand contributed to this process; (2) with the international ocean freight cost being decreased and the import tariffs being phased out yearly, the relatively high price in the domestic coal industry enhanced the demand for imported coal. Thus, domestic coal consumptions were affected and the price declined; (3) policy factor and other generating capacity reduced thermal power demand, which directly affected the demand for steam coal and then decreased the price; (4) consumptions of steam and coking coal were influenced by the slowing growth of GDP; (5) volatility of international oil price usually had an effect on coal price, and as substitutes, oil and natural gas would replace the coal demand owing to policy factors; (6) in the case that coal supply was greater than demand, oversupply would be translated to high port stocks, which exacerbated the depreciation of coal, indicating a decline in coal price. Moreover, we find "the total demand of coal" being in the center position, which will be affected by many factors and will affect other factors, inducing changes of coal price directly or indirectly.

\subsection{System Flow Diagram}

The causality diagram is mainly used for qualitative analysis, whereas the system flow diagram is mainly used for quantitative modeling. According to the causal relationship among various factors, we attempt to draw the system flow diagram of coal price, as shown in Figure 5. We derive an equation for each endogenous variable in the system flow diagram, and we introduce a constant or table function for each exogenous variable about the time " $T$ ". Then, by running the model, we can obtain the simulated data of coal price.

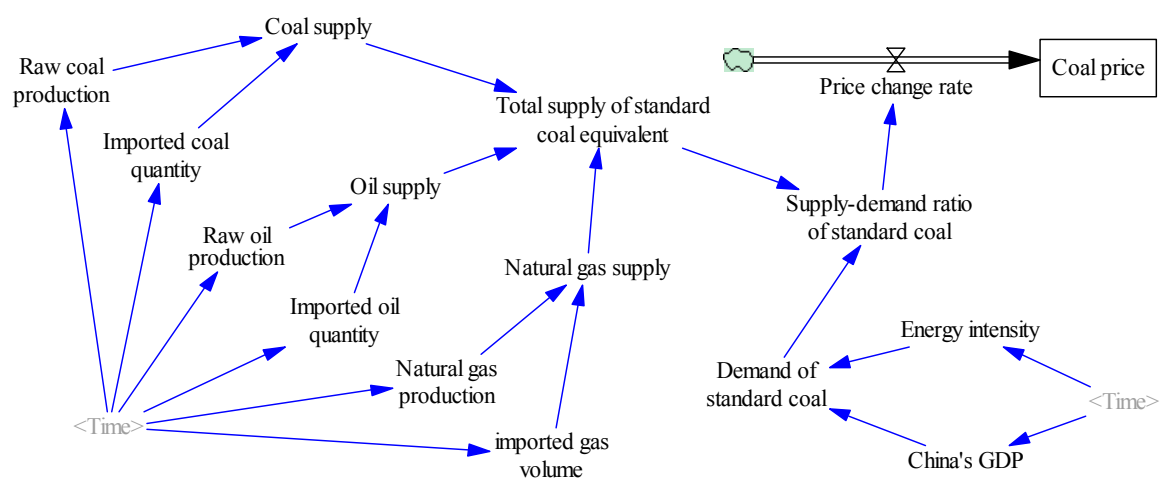

Figure 5. System flow diagram of coal price.

On one hand, we find that the three primary energy sources in China are mainly obtained via domestic output and foreign imports. The supply of coal, oil, and natural gas can be converted into the total supply of standard coal equivalent according to a certain ratio: $1 \mathrm{~kg}$ raw coal is equal to $0.7143 \mathrm{~kg}$ standard coal, $1 \mathrm{~kg}$ raw oil is equal to $1.4286 \mathrm{~kg}$ standard coal, and $1 \mathrm{~m}^{3}$ natural gas is equal to $1.2143 \mathrm{~kg}$ standard coal. On the other hand, we can derive the demand of standard coal based on the GDP of China and energy intensity (standard coal consumption per unit of GDP). Then, through the actual supply and the calculated demand, we can determine the supply-demand ratio of standard coal, which is relevant to the price change rate (price variation per unit time). Finally, the simulated coal price, which is an integral of the price change rate, can be obtained.

What should be noted is that several factors in the causality diagram do not appear as variables in the system flow diagram model. Nonetheless, this model can still reflect the influence from the five main factors analyzed previously. We can see that economic downturn directly decides the demand of standard coal, including steam coal, coking coal, and other primary energy sources. Meanwhile, 
the supply of coal, oil, and natural gas shows the overcapacity of coal and effect of substitutes. Moreover, to a certain extent, the supply-demand ratio could reflect the situation of coal stocks, particularly that of port stocks.

\section{Empirical Analysis}

\subsection{Data}

We selected 24 quarters from 2012 to 2017 as time units in our SD model. For all exogenous variables, we obtained data from relevant websites, such as Qinhuangdao coal net, National Bureau of Statistics of China site, and several other reliable websites [4,32,33]. The data of the first 16 quarters (2012-2015) are based on actuality, whereas those of the last 8 quarters (2016-2017) are predicted values in accordance with the existing data. The eight exogenous variables all used the table functions about time " $T$ ".

\subsection{System Dynamics Equations}

We applied SD equations to express quantitative relationships among different endogenous variables. First, in discussing the "price change rate", the relationship between price change rate and supply-demand is important given that the market decides the price. We used four indices to express supply-demand, namely, gap of supply and demand, ratio of supply and demand, gap rate, and ratio rate. These four indices were separately used along with actual price changes in SPSS to determine the optimum fitting curve. After multiple trials, we determined that the "ratio of supply and demand" and "price change rate" could best fit. The fitting equation is " $Y=-148,418.663 X^{3}+865,828.300 X^{2}$ $-2,126,456.268 X-2,283,630.020 e^{-X}+2,249,123.866$ " and $R^{2}=0.507$. The parameter estimates are shown in Table 2.

Table 2. Parameter estimates of price and supply-demand.

\begin{tabular}{ccccc}
\hline \multirow{2}{*}{ Parameter } & \multirow{2}{*}{ Estimate } & \multirow{2}{*}{ Standard Error } & \multicolumn{2}{c}{ 95\% Confidence Interval } \\
\cline { 3 - 5 } & & & the Lower Limit & the Upper Limit \\
\hline $\mathrm{a}$ & $-148,418.663$ & $424,372.583$ & $-1,082,456.419$ & $785,619.094$ \\
$\mathrm{~b}$ & $865,828.300$ & $2,563,947.501$ & $-4,777,382.100$ & $6,509,038.700$ \\
$\mathrm{c}$ & $-2,126,456.268$ & $6,429,622.530$ & $-16,277,960.041$ & $12,025,047.505$ \\
$\mathrm{~d}$ & $-2,283,630.020$ & $6,999,053.463$ & $-17,688,442.827$ & $13,121,182.787$ \\
$\mathrm{e}$ & $2,249,123.866$ & $6,864,842.289$ & $-12,860,292.139$ & $17,358,539.871$ \\
\hline
\end{tabular}

The SD Equations for endogenous variables are listed as follows:

$$
\text { Coal price }=\text { INTEG }(\text { Price change rate, } 782)
$$

Coal supply $=$ Raw coal production + Imported coal quantity

$$
\text { Demand of standard coal }=\text { China's GDP } \times \text { Energy intensity }
$$

Natural gas supply $=$ Natural gas production + Imported gas volume

$$
\text { Oil supply }=\text { Raw oil production + Imported oil quantity }
$$

$$
\begin{array}{r}
\text { Price change rate }=\begin{array}{r}
-148418.663 x^{3}+865828.300 x^{2}-2126456.268 x-2283630.020 e^{-x} \\
+2249123.866 \quad(x=\text { Supply-demand ratio of standard coal })
\end{array} \\
\begin{array}{r}
\text { Supply-demand ratio of standard coal }= \\
\text { Total supply of standard coal equivalent }
\end{array} \\
\text { Demand of standard coal }
\end{array}
$$




\subsection{Results and Error Test}

Figure 6 shows the obtained results. The blue line represents the simulated coal price within 24 quarters, and the red line represents the actual coal price of the first 17 quarters. Clearly, the simulated price curve has the same downward trend as the practical situation in the past four years (2012-2015). The curves are comparatively close to each other, which proved the accuracy of the SD model of coal price. What deserves to be explained is that there is an almost coincident trajectory of the simulation and of the real prices before the third quarter, even in the inflexion point of the second quarter. The main reasons are that China's coal prices are closer to the market in the second and third quarters, while in the fourth quarter, there are some influencing factors beyond the model due to some activities including winter heating, coal ordering in thermal power plants, and joint price elevation in coal enterprises. From the angle of the coal price model, we set the simulated coal price as 782 yuan/ton in the first quarter, which is very close to the real price. The simulation results are greatly affected by the real prices in the early stage of model operation, such as the second and third quarters. So we can see an almost coincident trajectory of the simulation and of the real prices before the third quarter, even in the inflexion point.

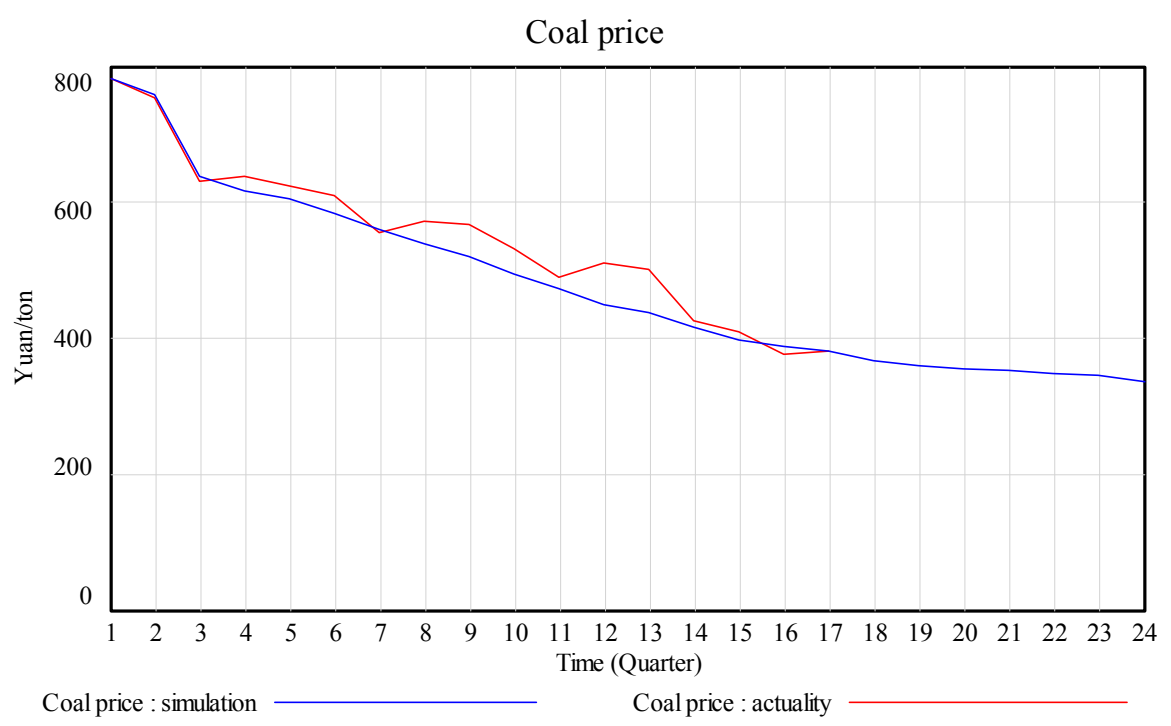

Figure 6. Comparison chart of simulated coal price and actual coal price.

According to the computational results of our SD model, we can also see that the simulated coal price shows a continuing downward trend in 2016 and 2017, with a slightly slower descent rate than the previous four years.

We applied the root mean square error (RMSE) to verify precision further. The formula of RMSE is expressed as:

$$
R M S E=\sqrt{\frac{\sum_{i=1}^{n}\left(\frac{y_{c i}-y_{i}{ }^{2}}{y_{i}}\right)^{2}}{n}}
$$

$y_{c i}$ means simulated coal price, $y_{i}$ means actual coal price, $n=1,2,3 \ldots, 17$.

The result of the error analysis is shown in Table 3. We obtained "RMSE $=5.61 \%$ ", this is relatively small and indicates good precision of the model. 
Table 3. Root mean square error (RMSE) analysis result of simulated coal price and actual coal price.

\begin{tabular}{ccccc}
\hline Quarter & $\begin{array}{c}\text { Simulated Coal Price } \\
\text { (yuan/ton) }\end{array}$ & $\begin{array}{c}\text { Actual Coal Price } \\
\text { (yuan/ton) }\end{array}$ & Relative Error & RMSE \\
\hline 1 & 782.00 & 781.7 & 0.0004 \\
2 & 759.25 & 752.7 & 0.0087 \\
3 & 639.50 & 632.3 & 0.0113 & \\
4 & 617.50 & 639.0 & -0.0336 \\
5 & 605.75 & 624.7 & -0.0303 & \\
6 & 583.00 & 611.3 & -0.0463 & \\
7 & 561.25 & 556.3 & 0.0088 & \\
8 & 539.00 & 572.7 & -0.0588 & \\
9 & 519.75 & 567.3 & -0.0839 & \\
10 & 495.50 & 533.3 & -0.0709 & \\
11 & 472.50 & 489.0 & -0.0337 & \\
12 & 450.00 & 512.0 & -0.1211 & \\
13 & 438.00 & 500.7 & -0.1252 & \\
14 & 415.50 & 424.7 & -0.0216 & \\
15 & 398.75 & 409.0 & -0.0251 & \\
16 & 388.00 & 376.7 & 0.0301 & \\
17 & 381.75 & 380.3 & 0.0037 & \\
\hline
\end{tabular}

\section{Discussion}

In this study, we analyzed the influencing factors of the declining coal price in the past four years, built a SD model of coal price, and conducted empirical analysis. Compared with the related literature referred in the Introduction section, our research has its own characteristics. First, most scholars examined energy price volatility through statistical and econometric methods and used test methods to verify the relationships among different variables. However, our study utilizes the SD method to clarify the relationships among the five factors and we ran a simulation with actual data. Second, several academics directly determined the effect of the price of substitutes on coal price by using detailed price data, whereas we expressed this effect through the supply-demand relationships of standard coal equivalents. Third, several scholars used the SD method to analyze the energy industry, but to the best of our knowledge, only a few scholars applied the SD method to examine the influencing factors of coal price, particularly the decreasing price in the past four years.

According to the predicted results of our SD model, the steam coal price will still decrease until 2017. Combined with the current macro economy, policy, and industrial restructuring situation, we analyzed the cause of the decreasing price, as follows:

(1) Economic factors: Currently, the high/middle-speed growth of China's economy has been the new normal. In accordance with economic theory, the pressure of each industry would transfer to the basic industry that is related to it. Thus, the coal industry would develop under the pressure of economic structure adjustment and enter a stage of "four periods," that is, slowing demand growth, overcapacity and inventory backlog, enhancing environmental constraints, and transforming the development mode.

(2) Energy policy factors: Controlling the total energy consumption and restricting the excessively rapid growth of coal consumption have been the cornerstones of the national energy policy since 2013. The Action plan for energy development strategy (2014-2020) released by the General Office of the State Council points out that the proportion of non-fossil energy consumption accounting for primary energy consumptions will reach $15 \%$ in 2020, natural gas consumption will reach more than $10 \%$, and coal consumption will be controlled within $62 \%$ from the current level of $65 \%$.

(3) Non-fossil energy factors: Generation of non-fossil energies will produce significant substitution effects on coal power. According to the power demand prediction made by Yuan et al., the power 
consumption of the entire society will reach 7.99 trillion $\mathrm{kWh}$ in 2020 and non-fossil energy generating capacity will account for $28.05 \%$ of total generation. This proportion will increase to $34.30 \%$ in 2030 and to $44.71 \%$ in 2050 [34]. Continuously improving the proportion of non-fossil energy generation could restrain the excessive growth of steam coal consumption effectively.

(4) Requirements for air pollutant disposal: The latest revision of China's atmospheric pollution prevention law has come into force since 1 January 2016. The revision clearly points out that we should adjust the energy structure, promote the production and use of clean energy, and gradually reduce the proportion of coal in primary energy consumptions. We should promote clean and efficient utilization of coal and reduce air pollutant emissions of coal production, usage, and transformation. Heat engine plants should adopt techniques of cleaner production and install devices for dust removal, desulfurization, and denitration. Moreover, power dispatching should prioritize clean energy.

(5) Requirements for greenhouse gas reduction: Low carbon and no carbon development has gradually become the mainstream of future energy technology. At present, the country with the most carbon emissions is China, which accounts for $24 \%$ of the world's total emissions, more than $80 \%$ of which is contributed by coal combustion. In November 2014, China and the US issued The Sino-US joint statement on climate change in Beijing. China proposed that national carbon emissions would reach its peak before 2030, but could reach this point as early as possible.

Coal demand growth is limited under the influence of various factors, and as a result, the steam coal price will probably keep decreasing for some time, which is consistent with the running results of our SD model.

Based on the actual situation of steam coal in China, the price, supply, and demand of the energy source is the concern of relevant stakeholders, namely, coal enterprises, thermal power plants, and intermediate transportation departments. For coal enterprises, controlling production and capacity reasonably for the near term is crucial. In the long term, these enterprises should improve the degree of mechanization, reduce the mining costs, extend the industry chain actively, and operate the enterprises efficiently. For thermal power plants, the falling steam coal price surely provides a good opportunity for profit. However, from the angle of energy conservation and emission reduction, thermal power plants are supposed to restrain the usage of high-sulfur and high-ash coal and introduce more efficient technologies of dust removal, desulfurization, and denitrification. Moreover, the power industry should keep the "big pressure on the small" measures and strengthen the phase out of small thermal power plants to improve energy efficiency and reduce pollutant emissions. Moreover, intermediate transportation departments should plan reasonably to reduce the high transportation cost of domestic coal, which could lead to the efficient connection of coal enterprises and electric power departments.

Constant low price of coal will bring great influence to China's energy reformation in the future. It is pointed out by the 13th "Five Year Plan of China's Energy Development that China's energy structure will transform to low-carbon type. This requires further decreasing coal demand, enlarging power generation scale of clean energy, and solving phenomenon of "wind, water and photovoltaic curtailment". However, low price of coal brings rich profit for coal-fired power plants and further stimulates their development. To promote selling of coal, coal-fired thermal power will also be used more frequently and steam coal demand also be improved under the guidance of regional protectionism policy in provinces with abundant coal resources. In this case, policy measures like further reinforcing of utilization technology of clean coal, perfecting of energy pricing system including coal price, discussing collection of a carbon tax or environmental tariff, and enhancing competitiveness of clean energy should be adopted emphatically to remit contradiction between development of coal power and clean energy and realize synergetic development of them under transforming to a low-carbon energy structure. 


\section{Conclusions}

This study aimed at determining the main factors causing the long-lasting plummet of the steam coal price since the second half of 2012, and on this basis, forecasting the price until the end of 2017 by using SD method. First, we introduced the background, research question, objectives, and contributions of this paper. We reviewed the literature in this part as well; Second, we qualitatively analyzed the five main factors of the declining price, including slowdown of GDP growth, coal overcapacity, weak demand for thermal power, effect of substitutes, and high stocks of port coal; Third, we built an SD model of coal price, drawing the causality diagram to determine the relationship among different factors and a system flow diagram for further quantitative analysis; Fourth, we conducted an empirical analysis. This part mainly included the data for exogenous variables, SD equations for endogenous variables, simulated results, and error analysis. Then, we discussed the results of our study and drew our conclusions.

Economic downturn, excessive production, weak demand, substitutes, and port stocks have been proven qualitatively and quantitatively as the main factors in the decline of coal prices. The supply and demand relationship is the foundation of our SD model. The combined actions of the five main factors caused the continuous decrease of the steam coal price. In addition, according to the running results of our SD model, the steam coal price will continue to decrease in the immediate future, with a slightly slower descent speed than before.

For future research, we intend to conduct empirical studies by using frequent data indicating monthly or even weekly information. Moreover, improving the applicability of the model for other energies, such as oil, natural gas, and electricity, is a possible extension for our future research.

Acknowledgments: This research was financially supported by the Fundamental Research Funds for Central Universities of China (Grant No. MS201439).

Author Contributions: Xiaopeng Guo designed the study and defined SD model. Yanan Wei prepared the data, participated in designing the study, wrote the manuscript, and revised it. Jiahai Yuan provided good advice for the paper.

Conflicts of Interest: The authors declare no conflict of interest.

\section{References}

1. Percentage Data of Coal Consumption. 2014; Available online: http://www.stats.gov.cn/tjsj/ndsj/2015/ indexch.htm (accessed on 7 July 2016).

2. Yuan, J.; Lei, Q.; Wang, Y. Electricity demand outlook and coal power prospect analysis under new economy normalcy in China. Energy China 2015, 37, 21-27. (In Chinese)

3. Wang, Z. Development of the coal industry under the new normal. China Energy News, 4 May 2015. (In Chinese).

4. Monthly Price of Steam Coal in Bohai Rim. 2012-2016. Available online: http:/ /osc.cqcoal.com/CoalIndex/ chs/new / (accessed on 7 July 2016).

5. Hasan, M.Z.; Akhter, S.; Rabbi, F. Asymmetry and persistence of energy price volatility. Int. J. Financ. Account 2013, 2, 373-378.

6. Wang, Y.; $\mathrm{Wu}, \mathrm{C}$. Forecasting energy market volatility using GARCH models: Can multivariate models beat univariate models? Energy Econ. 2012, 34, 2167-2181. [CrossRef]

7. Goor, H.V.; Scholtens, B. Modeling natural gas price volatility: The case of the UK gas market. Energy 2014, 72, 126-134. [CrossRef]

8. Kanamura, T. A supply and demand based volatility model for energy prices. Energy Econ. 2009, 31, 736-747. [CrossRef]

9. Zhang, K.; Mu, B. Price model of port steam coal. Ind. Mine Autom. 2013, 39, 30-38. (In Chinese)

10. Wang, D.; Zhang, Y.; Yin, Q.; Nie, R. Coal Price Volatility and Price Discovery Function in China. Resour. Sci. 2013, 35, 1643-1650. (In Chinese)

11. Zhang, Z.; Luo, S. Study on international and domestic energy price volatilities and their interrelationship based on VAR model and impulse function. China Min. Mag. 2013, 22, 34-37. (In Chinese) 
12. Zhou, W.; Luo, S. Dynamic impact of economic growth, domestic supply, foreigner dependence and alternative energy price on steam coal price: Empirical analysis on VAR model. China Min. Mag. 2013, 22, 33-36. (In Chinese)

13. He, L.; Li, Y. Characteristics of China's coal, oil and electricity price and its regulation effect on entity economy. Procedia Earth Planet. Sci. 2009, 1, 1627-1634.

14. Weng, F. Study on Market Reform Effect of Energy Price in China. Coal Econ. Res. 2012, 32, 51-56. (In Chinese)

15. Joëts, M.; Mignon, V. On the link between forward energy prices: A nonlinear panel cointegration approach. Energy Econ. 2012, 34, 1170-1175. [CrossRef]

16. García-Martos, C.; Rodríguez, J.; Sánchez, M.J. Modeling and forecasting fossil fuels, $\mathrm{CO}_{2}$ and electricity prices and their volatilities. Appl. Energy 2013, 101, 363-375. [CrossRef]

17. Zaklan, A.; Cullmann, A.; Neumann, A.; von Hirschhausen, C. The globalization of steam coal markets and the role of logistics: An empirical analysis. Energy Econ. 2012, 34, 105-116. [CrossRef]

18. Wang, Y.; Li, H.; Song, Q.; Qi, Y. The consequence of energy policies in China: A case study of the iron and steel sector. Resour. Conserv. Recy. 2015. [CrossRef]

19. Ouyang, X.; Lin, B. Impacts of increasing renewable energy subsidies and phasing out fossil fuel subsidies in China. Renew. Sustain. Energy Rev. 2014, 37, 933-942. [CrossRef]

20. Lin, B.; Ouyang, X. A revisit of fossil-fuel subsidies in China: Challenges and opportunities for energy price reform. Energy Convers. Manag. 2014, 82, 124-134. [CrossRef]

21. Yuan, C.; Liu, S.; Wu, J. The relationship among energy prices and energy consumption in China. Energy Policy 2010, 38, 197-207. [CrossRef]

22. Lee, S.; Chong, W.O. Causal relationships of energy consumption, price, and $\mathrm{CO}_{2}$ emissions in the U.S. building sector. Resour. Conserv. Recycl. 2016, 107, 220-226. [CrossRef]

23. Zhao, X.; Liu, L.; Wang, J.; Chen, X. Empirical Analysis about Influence Factors of Energy Consumption in China. Energy Procedia 2012, 17, 1255-1260.

24. $\mathrm{Xu}, \mathrm{J}$.; Li, X. Using system dynamics for simulation and optimization of one coal industry system under fuzzy environment. Expert. Syst. Appl. 2011, 38, 11552-11559. [CrossRef]

25. Yu, S.; Wei, Y. Prediction of China's coal production-environmental pollution based on a hybrid genetic algorithm-system dynamics model. Energy Policy 2012, 42, 521-529. [CrossRef]

26. Sverdrup, H.U.; Ragnarsdottir, K.V.; Koca, D. On modelling the global copper mining rates, market supply, copper price and the end of copper reserves. Resour. Conserv. Recycl 2014, 87, 158-174. [CrossRef]

27. Ansari, N.; Seifi, A. A system dynamics analysis of energy consumption and corrective policies in Iranian iron and steel industry. Energy 2012, 43, 334-343. [CrossRef]

28. Chi, K.C.; Nuttall, W.J.; Reiner, D.M. Dynamics of the UK natural gas industry: System dynamics modeling and long-term energy policy analysis. Technol. Forecast. Soc. 2009, 76, 339-357.

29. Špicar, R. System Dynamics Archetypes in Capacity Planning. Procedia Eng. 2014, 69, 1350-1355. [CrossRef]

30. Basic Data of Electric Power Statistics. 2011-2014. Available online: http://www.cec.org.cn/guihuayutongji/ tongjxinxi/ (accessed on 7 July 2016).

31. Data of Imported Coal Quantity. 2008-2015. Available online: http://coal.in-en.com/Stat/import/ (accessed on 7 July 2016).

32. Data of Imported Coal Price and National Coal Price. 2012-2016. Available online: http://www.sxcoal.com/ (accessed on 7 July 2016).

33. Data for Part of Exogenous Variables. 2012-2016. Available online: http://data.stats.gov.cn/easyquery.htm? cn=B01 (accessed on 7 July 2016).

34. Yuan, J.; Na, C.; Lei, Q.; Hu, Z. Coal use for power generation in China. Resour. Conserv. Recycl 2016. [CrossRef]

(C) 2016 by the authors; licensee MDPI, Basel, Switzerland. This article is an open access article distributed under the terms and conditions of the Creative Commons Attribution (CC-BY) license (http:/ / creativecommons.org/licenses/by/4.0/). 